\title{
Monoclonal Antibody Purification (Nicotiana benthamiana Plants)
}

Adam Husk ${ }^{1}$, Krystal Teasley Hamorsky ${ }^{1}$ and Nobuyuki Matoba2 ${ }^{*}$

\author{
${ }^{1}$ Owensboro Cancer Research Program at James Graham Brown Cancer Center, University \\ of Louisville School of Medicine, Owensboro, USA; ${ }^{2}$ Department of Pharmacology and \\ Toxicology, and Owensboro Cancer Research Program at James Graham Brown Cancer \\ Center, University of Louisville School of Medicine, Owensboro, USA \\ *For correspondence: n.matoba@louisville.edu
}

\begin{abstract}
[Abstract] Plant-based expression systems provide an alternative biomanufacturing platform for recombinant proteins (Matoba et al., 2011). In particular, plant virus-based vectors can overexpress proteins within days in the leaf tissue of Nicotiana benthamiana ( $N$. benthamiana). To overcome the issues of genetic instability and limited infectivity of recombinant viruses, Agrobacterium-mediated delivery of "deconstructed" virus vectors has become the mainstay for the production of large and/or multicomponent proteins, such as immunoglobulin (Ig)G monoclonal antibodies (mAbs). Here, we describe a method of producing human IgG mAbs in $N$. benthamiana using the tobamoviral replicon vector magnICON ${ }^{\circledR}$. The vector can express up to a few hundred $\mathrm{mg}$ of a mAb per $\mathrm{kg}$ of leaf material in 7 days. A representative case for the broadly neutralizing anti-HIV and anti-influenza mAbs, VRC01 and CR6261 respectively, is shown (Hamorsky et al., 2013). Leaf tissue is homogenized and the extract is clarified by filtration and centrifugation. The mAb is purified by fast protein liquid chromatography (FPLC) using Protein A affinity and Phenyl HP hydrophobic interection resins.
\end{abstract}

\section{Materials and Reagents}

1. Agrobacterium tumefaciens electrocompetent cells (strain GV3101)

2. MagnICON ${ }^{\circledR}$ plasmid (Icon Genetics $\mathrm{GmbH}$, catalog number: plCH38099) (Marillonnet et al., 2004; Giritch et al., 2006)

3. Rifampicin (Sigma-Aldrich, catalog number: R3501)

4. Gentamicin (Sigma-Aldrich, catalog number: G1264)

5. Kanamycin (Sigma-Aldrich, catalog number: K1876)

6. Yeast Extract (Fisher Scientific, catalog number: BP1422)

7. Nutrient Broth (BD, catalog number: 231000)

8. UV/Vis cuvette (VWR International, catalog number: 77776-745)

9. MES (EMD Millipore, catalog number: 475894)

10. Magnesium sulfate (EMD Millipore, catalog number: MX0070-3)

11. Sodium phosphate (EMD Millipore, catalog number: $S X 0710-1)$

12. Sodium chloride (Sigma-Aldrich, catalog number: S9888) 


\author{
13. Sodium hydroxide \\ 14. Ascorbic acid (Fisher Scientific, catalog number: BP351) \\ 15. $1 \mathrm{M}$ Tris buffer $(\mathrm{pH} 8.0)$ \\ 16. Glycine (Fisher Scientific, catalog number: BP381-5) \\ 17. L-Arginine (Sigma-Aldrich, catalog number: A5006) \\ 18. Dulbecco's Phosphate Buffered Saline (DPBS) (Gibco ${ }^{\circledR}$, catalog number: 14190-144) \\ 19. LB agar plate (see Recipes) \\ 20. YenB media (see Recipes) \\ 21. Infiltration buffer (see Recipes) \\ 22. Extraction buffer (see Recipes) \\ 23. Protein A elution buffer (see Recipes) \\ 24. Protein A equilibration/wash buffer (see Recipes) \\ 25. Phenyl HP equilibration/wash buffer (see Recipes) \\ 26. Phenyl HP elution buffer (see Recipes )
}

\title{
Equipment
}

1. Amicon Ultra centrifugal filter, $30 \mathrm{~K}$ (EMD Millipore, catalog number: UFC903024)

2. Electroporation cuvette (USA Scientific, catalog number: 9104-1050)

3. Bottle top filter unit (VWR International, catalog number: 73520-986)

4. Beveled flask (VWR International, catalog number: 4446-500)

5. Centrifuge bottles (Thermo Fisher Scientific, catalog number: 3141-0250)

6. HiTrap Protein A HP column (General Electric Company, catalog number: 17-040303)

7. Phenyl HP column (General Electric Company, catalog number: 17-5195-01)

8. Multiporator (Eppendorf, Bacteria module, catalog number: 4308 805.005)

9. $28{ }^{\circ} \mathrm{C}$ Incubator (Fisher Scientific)

10. Benchtop orbital shaker (Thermo Fisher Scientific, catalog number: SHKE4450)

11. UV/Vis spectrophotometer (Beckman Coulter, catalog number: DU800)

12. Avanti ${ }^{\circledR}$ J-26 XP Centrifuge (Beckman Coulter, catalog number: 393124)

13. Infiltration apparatus (Bel-Art Products, catalog number: F420250000)

14. Vacuum pump (William H. Welch Medical Library, catalog number: 8890A-75)

15. Growth chamber

16. Blender (Waring Pro, catalog number: $7011 \mathrm{HS}$ )

17. AKTA purifier (General Electric Company, catalog number: 28-4062-66)

\section{Procedure}

1. Transform electrocompetent agrobacteria cells with plant-expressing viral vector DNA plasmid containing the sequence for the $\mathrm{mAb}$ of interest at $2,000 \mathrm{~V}$ for $5 \mathrm{msec}$. 
2. After shaking transformed cells for $1 \mathrm{~h}$ at $28^{\circ} \mathrm{C}$ to establish antibiotic resistance, streak cells on LB agar plates (containing $30 \mu \mathrm{g} / \mathrm{ml}$ Rifampicin, $50 \mu \mathrm{g} / \mathrm{ml}$ Gentamicin and $50 \mu \mathrm{g} / \mathrm{ml}$ Kanamycin) and grow in $28^{\circ} \mathrm{C}$ incubator for $3-4$ days.

3. Pick a single transformed bacterial colony and grow in $5 \mathrm{ml}$ of YenB media plus 30 $\mu \mathrm{g} / \mathrm{ml}$ Rifampicin and $50 \mu \mathrm{g} / \mathrm{ml} \mathrm{Kanamycin} \mathrm{at} 28^{\circ} \mathrm{C}$ and $225 \mathrm{rpm}$ overnight.

4. Transfer $5 \mathrm{ml}$ starter culture to large flask containing $95 \mathrm{ml}$ fresh YenB media plus the same antibiotics and grow at $28^{\circ} \mathrm{C}$ and $225 \mathrm{rpm}$ overnight.

5. Measure the optical density at $600 \mathrm{nM}$ using UV/Vis Spectrophotometer using YenB media as a blank. Calculate the volume of the large culture required for a final $\mathrm{OD}_{600}$ equal to 0.03 in the total volume of infiltration buffer needed (1.6 L).

6. Centrifuge calculated volume of bacterial culture at $5,000 \times \mathrm{g}$, room temperature for 15-30 min. Re-suspend the pelleted bacteria in any volume of infiltration buffer and dilute to final volume of $1.6 \mathrm{~L}$.

Note: For example, if measure $O D_{600}$ is 1.25 then the following calculation would be made

(1.25) $x=(0.03)(1.6 L)$

$x=38.4 \mathrm{ml}$ of bacterial culture would need to centrifuged then re-suspended in infiltration buffer.

7. Transfer the re-suspended bacteria to vacuum apparatus and fill to final volume. Apply 25 inches $\mathrm{Hg}$ of pressure to all the leaves of an entire $\mathrm{N}$. benthamiana plant (between 26-30 days old) for 2 min then release the vacuum causing the bacterial inoculum to enter the leaves (Figure 1). The same infiltration buffer can be re-used for up to approximately 16 plants without any noticeable depreciation in inoculation.

Note: Efforts should be made to keep plant soil from entering infiltration buffer but it will not interfere with successfully infecting plants.



Figure 1. Vacuum Infiltration. The $\mathrm{mAb}$ vector is delivered via $A$. tumefaciens into $N$. benthamiana leaves using vacuum infiltration (see above, procedure step 7 ).

8. Plants are grown post-infiltration the same as before infiltration, at $27^{\circ} \mathrm{C}$ and $>50 \%$ humidity following a $16 \mathrm{~h}$ daytime/8 $\mathrm{h}$ nighttime schedule. Water the plants every other day. 
9. At 7 days post infiltration (dpi), harvest the infected leaves expressing mAb by cutting the leaves at the base of the stem and measure the total mass. Inoculated leaves are distinguishable by the mosaic phenotype displayed after 4-5 days post infiltration compared to non-inoculated leaves.

10. $\mathrm{mAb}$ is extracted in cold extraction buffer by using an industrial blender while mixing 2 $\mathrm{ml}$ buffer for every $1 \mathrm{~g}$ leaf tissue.

Note: For the remaining duration of the procedure, all efforts are made to ensure the $m A b$ remains at $4{ }^{\circ} \mathrm{C}$ including extraction and purification.

11. The leaf extract is centrifuged at $15,000 \times \mathrm{g}$ for $10 \mathrm{~min}$ at $4{ }^{\circ} \mathrm{C}$ to pellet plant debris.

12. The partially clarified extract is $\mathrm{pH}$ adjusted to 7.0 using sodium hydroxide and centrifuged at $15,000 \times \mathrm{g}$ for $10 \mathrm{~min}$ at $4{ }^{\circ} \mathrm{C}$ to pellet starches and small plant debris.

13. The final step of extraction requires the clarified extract to be passed through a 0.2 $\mu \mathrm{m}$ bottle top filter using a vacuum.

14. mAb is purified initially by using a HiTrap Protein A HP column from GE Healthcare via FPLC on an AKTA purifier. The column is equilibrated with 10 column volume (CV) of Protein A Equilibration/Wash buffer.

15. $\mathrm{mAb}$ clarified extract is loaded at $2 \mathrm{ml} / \mathrm{min}$. After the extract has been loaded to the column, unbound proteins are washed out of the column using Protein $A$ Equilibration/Wash buffer (10 CV).

16. Protein $A$ Elution buffer is used to elute $m A b$ from the Protein $A$ column using a step gradient to $100 \%$ Protein A Elution buffer for $10 \mathrm{CV}$. The $\mathrm{pH}$ is adjusted from 3.0 to 7.0 using $1 \mathrm{M}$ Tris buffer $(\mathrm{pH} \mathrm{8.0)}$ ) for the fractions containing mAb.

Note: A step gradient is programmed into the method run so that the AKTA purifier transitions from $0 \%$ elution buffer to $100 \%$ elution buffer in a single step.

17. Following Protein A purification, a HiTrap Phenyl HP column from GE Healthcare is utilized. The column is equilibrated with $10 \mathrm{CV}$ in Phenyl HP Equilibration/Wash buffer.

18. Protein $A$ eluted $m A b$ is diluted $1: 10$ in Phenyl HP Equilibration/Wash buffer and loaded at $2 \mathrm{ml} / \mathrm{min}$. Unbound protein is washed off of the column using $10 \mathrm{CV}$ Phenyl HP Equilibration/Wash buffer.

19. Phenyl HP Elution buffer is used to elute $\mathrm{mAb}$ from the column using a linear gradient from 0\% Phenyl HP Elution buffer to 100\% Phenyl HP Elution buffer over $30 \mathrm{CV}$ followed by an additional $5 \mathrm{CV}$ at $100 \%$ Phenyl HP Elution buffer.

Note: A linear gradient is programmed into the method run so that the AKTA purifier controls the incremental transition from $0 \%$ elution buffer to $100 \%$ elution buffer for which the entire length of elution is $30 \mathrm{CV}$.

20. Purified mAb is formulated into Dulbecco's phosphate buffered saline (DPBS) pH 7.2. Purity is analyzed by densitometry of an overloaded Coomassie-stained sodium dodecyl sulfate polyacrylamide gel electrophoresis (SDS-PAGE) under reducing and non-reducing conditions. 
21. Activity is determined by antigen capture enzyme-linked immunosorbent assay (ELISA), surface plasmon resonance and in vitro virus neutralization assays.

\section{$\underline{\text { Recipes }}$}

1. LB agar plate

$30 \mu \mathrm{g} / \mathrm{ml}$ Rifampicin

$50 \mu \mathrm{g} / \mathrm{ml}$ Gentamicin

$50 \mu \mathrm{g} / \mathrm{ml}$ Kanamycin

2. YenB media (for $1 \mathrm{~L}$ )

Yeast Extract $7.5 \mathrm{~g}$

Nutrient Broth $8.0 \mathrm{~g}$

$\mathrm{pH} 7.0$

Autoclave

3. Infiltration buffer

$10 \mathrm{mM}$ MES

$10 \mathrm{mM}$ Magnesium Sulfate

pH 5.5

4. Extraction buffer

100 mM Sodium Phosphate

100 mM Sodium Chloride

$40 \mathrm{mM}$ Ascorbic Acid

pH 6.0

5. Protein A Elution buffer

100 mM Glycine

$200 \mathrm{mM}$ L-Arginine

$\mathrm{pH} 3.0$

6. Protein A Equilibration/Wash buffer

20 mM Sodium Phosphate

$\mathrm{pH} 7.0$

7. Phenyl HP Equilibration/Wash buffer

50 mM Sodium Phosphate

$1 \mathrm{M}$ Ammonium Sulfat

$\mathrm{pH} 7.0$

8. Phenyl HP Elution buffer

50 mM Sodium Phosphate

$\mathrm{pH} 7.0$ 


\section{Acknowledgments}

This protocol was adapted from Hamorsky et al. (2013). The magnICON vectors were provided from Icon Genetics $\mathrm{GmbH}$, Halle/Saale, Germany. This work was made possible in part by NIH R21/R33AI088585 and a University of Louisville Office of Vice President for Research Competitive Enhancement Grant (50730) to NM.

\section{References}

1. Giritch, A., Marillonnet, S., Engler, C., van Eldik, G., Botterman, J., Klimyuk, V. and Gleba, Y. (2006). Rapid high-yield expression of full-size IgG antibodies in plants coinfected with noncompeting viral vectors. Proc Natl Acad Sci U S A 103(40): 14701-14706.

2. Hamorsky, K. T., Grooms-Williams, T. W., Husk, A. S., Bennett, L. J., Palmer, K. E. and Matoba, N. (2013). Efficient single tobamoviral vector-based bioproduction of broadly neutralizing anti-HIV-1 monoclonal antibody VRC01 in Nicotiana benthamiana plants and utility of VRC01 in combination microbicides. Antimicrob Agents Chemother 57(5): 2076-2086.

3. Matoba, N., Davis, K. R. and Palmer, K. E. (2011). Recombinant protein expression in Nicotiana. Methods Mol Biol 701: 199-219.

4. Marillonnet, S., Giritch, A., Gils, M., Kandzia, R., Klimyuk, V. and Gleba, Y. (2004). In planta engineering of viral RNA replicons: efficient assembly by recombination of DNA modules delivered by Agrobacterium. Proc Natl Acad Sci U S A 101(18): 68526857. 